\title{
Mapping the intra-habitat variation of leaf mass loss rate in a brackish Mediterranean lake
}

\author{
L. Rossi* , M. L. Costantini \\ Dipartimento di Genetica e Biologia Molecolare, Sez. Ecologia, Università di Roma ‘La Sapienza', Via dei Sardi 70, \\ 00185 Roma, Italy
}

\begin{abstract}
To study patterns of spatio-temporal variation of both leaf breakdown and interactions between leaf-associated detritivores and fungi, we mapped the variation of the mass loss rate of Phragmites australis in a brackish Mediterranean lake. We carried out the study at 20 sampling points randomly chosen on a $400 \mathrm{~m}^{2}$ grid on the bottom of Lake Alimini, using litterbags which contained reed leaves. The mass loss from litterbags after $30 \mathrm{~d}$, leaf-colonizing animals, and the microbial activity on the reed litter were assessed seasonally over a year in each sampling site. Half of the litterbags were protected from animal colonisation and used to determine the mass loss due solely to microbial activity and abiotic factors. The benthic detritivores colonizing the remaining litterbags were collected and sorted by their functional group. Microbial respiration on protected and unprotected litterbags and the sediment organic content were measured at each sampling site and related to litter mass loss. Comparisons of mass loss and microbial oxygen consumption between protected and unprotected litterbags indicated that leaf processing was affected by the grazing activity of detritivores on microflora. Hydrological conditions and the potential litter distribution influenced detritivore occurrence which, in turn, controlled the litter processing. The observed between-site variance in the reed mass loss showed that, beside the rate, spatial variation is an important process feature in the habitat description. Geostatistics based on either the average values or the temporal variation of the mass loss rate provided 2 different, statistically validated lake topographies. However the latter was more convenient for outlining site differences within the lake. The extent of reed cover along the shore, as well as variable freshwater and nutrient inputs, determined the intra-habitat variability. We suggest an index (RL), integrating 3 critical factors for the allochthonous detritus processing (i.e. distance, sinuosity, and plant cover of the shore), as an indirect estimate of the rate of detritus mass loss. This can facilitate the approach to the functional geography of aquatic ecosystems.
\end{abstract}

KEY WORDS: Brackish lake $\cdot$ Leaf mass loss $\cdot$ Intra-habitat heterogeneity $\cdot$ Microorganism-detritivore interactions $\cdot$ Riparian influence

\section{INTRODUCTION}

Landscape ecology considers habitats to be homogeneous basic patches. However, habitats are not functionally homogeneous and their inner complexity needs to be incorporated into simulation models to optimize land-use management (Li \& Reynolds 1994, Turner et al. 1995). Many current models of landscape management deal with variation at the population level, often neglecting processes which characterize

*E-mail: rossilre@axrma.uniroma1.it ecosystems and reflect their functions (e.g. productivity and decomposition, Turner 1989). Conversely, describing the intra-habitat pattern of ecosystem processes is crucial for evaluating the environment's functional heterogeneity, because these processes integrate biotic and abiotic changes, showing different spatial and temporal patterns as the scale of observation changes (Watt 1947, Levin 1992, Li \& Reynolds 1994).

Detritus is a major source of energy for many ecosystems and, among ecosystem processes, detritus decomposition largely contributes to the metabolism of shallow waters. Decomposition is a complex process 
that occurs through different phases and depends on many environmental factors. The roles of microbial and animal communities as well as all physical factors have been emphasized by several studies (e.g. Valiela et al. 1985, Webster \& Benfield 1986, Mann 1988). The decomposition rate is also influenced by the quality and concentration of the biochemical substrate (sensu Saunders 1980), which vary on spatio-temporal scales, depending on the riparian vegetation cover (Cummins et al. 1989), the main source of allochthonous input for shallow waters. Hence, to predict the space-time variation of decomposition within a habitat, the role of timing, quantity, and spatial distribution of the detritus input source needs also to be considered.

The present work is focused on intra-habitat variation of leaf mass loss during decomposition in a coastal brackish lake. We studied the $30 \mathrm{~d}$ mass loss of Phragmites australis litter and the litter colonizers across Lake Alimini, which is located along the southeastern Italian coast. We investigated the relationships between the reed mass loss and the habitat heterogene-

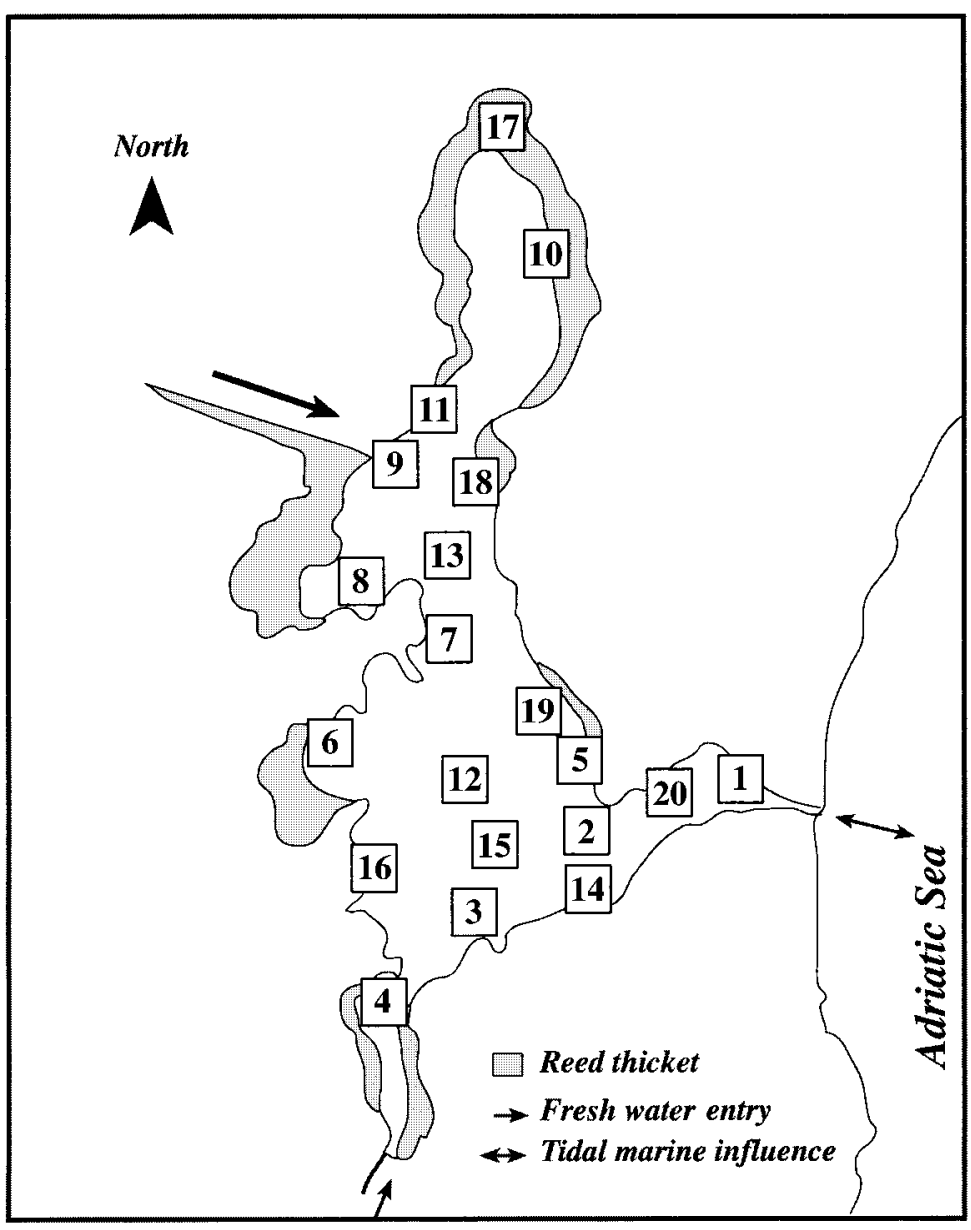

Fig. 1. Map of Lake Alimini showing the station positions and the Phragmites australis plant distribution (shaded area). Scale: $1 \mathrm{~cm}=300 \mathrm{~m}$ ity, due to salinity, sediment type, distance from shore, and shore vegetation cover and sinuosity. The field sampling was designed to determine the spatial distribution of the mass loss rate of the most common macrophyte as well as the role of microorganism-animal interactions in this process. Geostatistical analysis was used to obtain the most probable maps of the processing rate, in the search for a new functional geography of water ecosystems based on the intra-habitat spatial and temporal variation of an ecosystem process.

\section{MATERIALS AND METHODS}

Study habitat. The study was carried out in Lake Alimini, a coastal brackish lake located in southern Italy on the Adriatic Sea $\left(40^{\circ} 11^{\prime} 26.52^{\prime \prime}\right.$ to $40^{\circ} 13^{\prime} 12.72^{\prime \prime} \mathrm{N}$, $18^{\circ} 26^{\prime} 13.64^{\prime \prime}$ to $18^{\circ} 27^{\prime} 19.88^{\prime \prime}$ E; Fig. 1). Lake Alimini is $3.03 \mathrm{~km}$ long and has a maximum width of $1.34 \mathrm{~km}$. The lake shape is very irregular and the ratio of the length of shoreline to the area of the water body indicates a potential high riparian impact on the whole lake ecology. The water surface is about $1.26 \mathrm{~km}^{2}$ depending on both water level, which varies according to tidal cycles (about $120 \mathrm{~cm}$ ), and water inflow from tributaries. The maximum depth is $3.5 \mathrm{~m}$. The lake receives freshwater inputs from an elevated dock named 'Fontanelle' on the southwestern side and several drainage canals from the catchment basin on the northern side. Since freshwater enters in the southern area, stagnation events characterize the northern area where inputs of freshwater are ephemeral due to drainage of surrounding fields, which are exploited for agricultural purposes (see also Macchia 1967). Nutrient concentrations, measured at 8 lake sites during our field study, are reported in Table 1 (Magazzù \& Vadrucci pers. comm.). The lake is separated from the sea by a thin belt of Pliocene sandy dunes and is almost entirely surrounded by rocky shores. During the study period, canals communicating with the sea occasionally silted up. A gradient ranging from a sandy to muddy bottom runs from the shore to the basin center. Vegetation is not evenly distributed along the shore. Mediterranean bush (chaparral), mainly dominated by Quercus coccifera L., Cistus monspeliensis L., Pistacia lentiscus L., Rosmarinus officinalis L., Erica arborea L. and E. verticillata Forsskal, stretches from the bare rock edges. Marshy areas are distributed along 
Table 1. Nutrient concentration (mean \pm SD) in Lake Alimini during the experimental study (see Fig. 1 for the site location).

Data collected by Magazzù \& Vadrucci (pers. comm.)

\begin{tabular}{|cccccc|}
\hline Site & $\begin{array}{c}\mathrm{NH}_{3}, \mathrm{NH}_{4}{ }^{+} \\
(\mu \mathrm{M})\end{array}$ & $\begin{array}{c}\mathrm{NO}_{2}{ }^{-} \\
(\mu \mathrm{M})\end{array}$ & $\begin{array}{c}\mathrm{NO}_{3}{ }^{-} \\
(\mu \mathrm{M})\end{array}$ & $\begin{array}{c}\mathrm{PO}_{4}{ }^{3-} \\
(\mu \mathrm{M})\end{array}$ & $\begin{array}{c}\mathrm{Si}(\mathrm{OH})_{4} \\
(\mu \mathrm{M})\end{array}$ \\
\hline 9 & 2.36 & 1.02 & 19.04 & 0.05 & 37.36 \\
& $(0.80)$ & $(0.13)$ & $(8.24)$ & $(0.04)$ & $(26.30)$ \\
14 & 2.24 & 1.15 & 11.99 & 0.06 & 33.92 \\
& $(0.88)$ & $(0.14)$ & $(5.20)$ & $(0.09)$ & $(17.78)$ \\
15 & 1.91 & 1.02 & 14.01 & 0.07 & 32.71 \\
& $(1.13)$ & $(3.68)$ & $(0.24)$ & $(6.62)$ & $(0.14)$ \\
16 & 2.24 & 1.11 & 13.89 & - & 28.97 \\
& $(1.18)$ & $(0.23)$ & $(4.90)$ & - & $(21.68)$ \\
17 & 5.45 & 1.15 & 22.07 & 0.17 & 72.53 \\
& $(3.88)$ & $(0.62)$ & $(9.72)$ & $(0.19)$ & $(56.51)$ \\
18 & 2.26 & 1.14 & 9.24 & 0.01 & 28.54 \\
& $(1.03)$ & $(0.15)$ & $(2.71)$ & $(0.04)$ & $(14.63)$ \\
19 & 2.00 & 1.13 & 11.41 & 0.04 & 27.20 \\
& $(0.67)$ & $(0.18)$ & $(5.19)$ & $(0.08)$ & $(15.61)$ \\
20 & 2.04 & 1.13 & 9.30 & 0.03 & 27.50 \\
& $(0.92)$ & $(0.18)$ & $(6.06)$ & $(0.04)$ & $(20.25)$ \\
\hline
\end{tabular}

the basin perimeter mainly on the northern side, where 2 concentric bands of vegetation can be distinguished. The inner belt is constituted exclusively by the reed Phragmites australis (Cav.) Trin. ex Steud (also known as $P$. communis (L.) Trin.), whereas in the outer belt Cladium mariscus (L.) Pohl, Scirpus holoschoenus L. and Cyperus longus L. dominate (Macchia 1967, Marano et al. 1974). Phragmites australis is also concentrated along the northwestern freshwater channel, which is often affected by drought. Plant detritus, mainly represented by Phragmites litter, is the most important energy input for the lake. However, the reed distribution varies around the lake (Fig. 1), and the ratio of the length of shoreline to the area of the water body differs between the northern and southern halves of the lake $\left(9.20\right.$ vs $\left.7.05 \mathrm{~km} / \mathrm{km}^{2}\right)$. This suggests a greater riparian impact on the water body in the former than in the latter. The widest vegetated areas, covered by Phragmites, are located in the northern swamps and close to the main northern freshwater input (8.05 and 4.52 hectares, respectively). On the whole, the perimetric reed thicket cover is considerably higher on the northern side than on the southern one (vegetatedunvegetated shoreline ratio: 0.935 vs 0.256 ), causing heterogeneous litter distribution along the lake belt.

Lake Alimini is used as an extensive aquaculture basin to rear commercially valuable fish such as Dicentrarchus labrax (L.), Sparus aurata L., Anguilla anguilla (L.) and Mugil cephalus L. It is also an important natural reserve for bird species since it is located on one of the main migratory routes. Tourist activities are substantial during the summer.
Sample collection and detritus processing assessment. Twenty sample sites were chosen on a $400 \mathrm{~m}^{2}$ grid taking into account 4 sources of environmental variation: reed distribution, salinity, depth, and sediment type. Some sites were located within or on the edge of the reed thicket at 15 to $40 \mathrm{~cm}$ depth (Fig. 1). In the present paper we report data collected seasonally from June 1995 to May 1996.

Samples of the upper sediment layer $(5 \mathrm{~cm}$ thick) were collected at each site every 2 mo. The assessment of the grain size was carried out by sieving, using sieves with mesh sizes of 1 and $0.5 \mathrm{~mm}$. The percentage of organic matter ( $\%$ ash-free dry mass) in the 2 sediment fractions was determined after ignition in a muffle furnace at $500^{\circ} \mathrm{C}$ for $6 \mathrm{~h}$ to prevent the loss of carbonate (Rosa et al. 1994).

The processing of dead leaves of Phragmites australis was studied measuring mass loss from litterbags (Bocock \& Gilbert 1957, Petersen \& Cummins 1974), a technique that we have already utilized in freshwater, brackish and marine environments (Rossi et al. 1987, Fazi \& Rossi 1996). Standing dead leaves were collected in January 1995 from the senescent plants, sorted for age and stored until use. Ten $\mathrm{cm}$ long brown leaf fragments were oven-dried at $60^{\circ} \mathrm{C}$ for $72 \mathrm{~h}$ and weighed to the nearest $0.001 \mathrm{~g}$. Thirty litterbags (each containing $2 \pm 0.001 \mathrm{~g}$ dry mass leaves) for each of the 20 sites were prepared every season; one half (15) were protected with a nylon mesh of $0.1 \mathrm{~mm}$ to prevent colonization by benthic invertebrates. The litterbags were then randomly placed at each sampling site on the lake bottom to simulate the natural heaps of detritus. After 10, 20, and $30 \mathrm{~d}$ of submersion, 5 protected and 5 unprotected litterbags per site were carefully collected by hand, to prevent vagile invertebrates from escaping, and placed separately in polyethylene bags. Sample collection at the deepest sites was carried out using SCUBA. In the laboratory, macroinvertebrates associated with each unprotected pack were gently washed and observed under a microscope, then sorted according to taxon, size, and functional role (sensu Cummins 1974), and then enumerated. The functional role of macroinvertebrates was assigned according to published reports of trophic habits (Riedl 1991). Three unprotected and 3 protected litterbags per sampling were used to evaluate detritus mass loss. The dry mass (at $60^{\circ} \mathrm{C}$ for $72 \mathrm{~h}$ ) and the ash content (after ignition in a muffle furnace at $500^{\circ} \mathrm{C}$ for $6 \mathrm{~h}$ ) of each litterbag and each associated animal species were determined to assess the ash-free dry mass (AFDM). The remaining litterbags were used to assess both the density and respiration activity of leaf-colonizing microflora. Twenty leaf discs $(0.5 \mathrm{~cm}$ in diameter) per litterbag from each site were incubated in a moist chamber for $4 \mathrm{~d}$ at $18^{\circ} \mathrm{C}_{i}$ then the percentage of leaf discs with sporulating fungi 
was determined. The microbial oxygen demand was determined on leaf fragments. These were gently washed to remove sediment and placed, tied with a sterile nylon thread, in $250 \mathrm{ml}$ Winkler bottles filled with water from the sample sites, previously sterilized by filtration and $\mathrm{O}_{2}$ saturated. Control bottles were similarly prepared with autoclaved fragments from the same litterbag. All the bottles were held in the dark for $3 \mathrm{~h}$ at the temperature recorded in the sites. Then, to avoid chemical interference with Winkler reagents (Fazi \& Rossi 1996) the fragments were carefully removed by the thread from the bottles before oxygen fixation. The leaf fragments were oven-dried and weighed. The amount of $\mathrm{O}_{2}$ consumed was obtained as the difference from the control oxygen content and referred to leaf unit mass. The measures were made on 3 replicate leaf fragments from each litterbag.

Salinity, temperature and dissolved $\mathrm{O}_{2}$ were determined in all sample sites at noon by means of field instruments. Riparian morphometry and vegetation cover (reed thicket) were checked both by field observations and on the existing small scale (1:1000) topographic and thematic maps.

Data analyses. Decomposition: The fit of 2 classical decomposition models (Carpenter 1982) to the data was determined by regression analysis between remaining detrital AFDM and time.

(1) Exponential model:

$$
M_{t}=M_{0} \mathrm{e}^{-k t}
$$

where $M_{0}$ is the initial leaf mass, $M_{t}$ is the remaining AFDM at the time $t$ (in days) and $k$ is the decomposition coefficient expressed as $\mathrm{d}^{-1}$. The half-life is expressed as $\ln (2) / k$ (time necessary for the reed leaf mass to decrease to $50 \%$ of its initial AFDM, from the exponential model) (Olson 1963, Gallardo \& Merino 1993).

(2) Composite exponential:

$$
M_{t}=\left(M_{0}-R\right) \mathrm{e}^{-K L t}+R \mathrm{e}^{-K R t}
$$

where $R$ is the mass of the refractory part of detritus and $L$ is the labile one (Lousier \& Parkinson 1976). KR and $K L$ are the respective decomposition coefficients.

One hundred and sixty mass loss equations (20 sites $\times$ 4 seasons $\times 2$ treatments) were obtained from the model giving the best fit to the collected data. Differences were verified by ANCOVA after log-transforming data.

Differences in both environmental and detritus processing parameters among sample sites were verified by 1-way ANOVA. A 2-way ANOVA was applied to detect differences among treatments (protected and unprotected litterbags) or seasons.

The temporal variability of decomposition coefficient, half-life time, and sediment organic matter were expressed as the coefficient of variation: $\mathrm{CV}=(\mathrm{SD} /$ mean)*100. A variance-ratio test was used for variability comparisons (Zar 1984).

Animals and sediments: Similarities of animal abundance and sediment organic contents among sites were determined by farthest neighbor cluster analysis on Euclidean distance matrices. A K-means clustering was performed for the statistical validation by 1-way ANOVA.

Riparian features: To obtain a measure of the potential riparian influence on the water basin, we subdivided the lake perimeter into 100 segments (95 m long being the maximum segment length showing the best accuracy of sinuosity measure on available topographic maps) and used the following formula, hereafter called 'RL' index:

$$
\mathrm{RL}=\frac{\sum_{L=1}^{N} \frac{L_{\mathrm{rl}}}{L_{\mathrm{dl}}} \times \frac{1}{D l}}{N} \times \frac{L_{\mathrm{c}}}{L_{\mathrm{r}}}
$$

where $N=$ number of segments closer to the sampling site than to adjacent sites, $L_{\mathrm{rl}}=$ real length of segment $L$ (in this case it is $95 \mathrm{~m}$ ), $L_{\mathrm{dl}}=$ linear distance between the 2 extremities of segment $L, D l=$ minimum distance from the sampling site to segment $L_{1} L_{\mathrm{C}}=$ number of reedcovered segments among the $N$ segments, $L_{\mathrm{r}}=$ number of reed-uncovered segments among the $N$ segments.

The formula took into account 3 major shoreline characteristics crucial for allochthonous detritus processing, namely distance of site from the shoreline, sinuosity and vegetative cover of the shoreline segments involved. The $L_{\mathrm{rl}} / L_{\mathrm{dl}}$ ratio indicates the degree of water-land interactions due to sinuosity, whereas the $L_{\mathrm{C}} / L_{\mathrm{r}}$ ratio indicates the potential allochthonous detritus input due to the reed cover along the coastline segment involved. Relative to a sampling site, the 'RL' index is high when the distance of site from the shoreline is small, and both the percentage of reed cover and the sinuosity high.

Mapping: Geostatistics were used as quantitative tool for evaluating the spatial variation of variables, i.e. at which extent variables measured close to one another were more similar than those measured farther away. The degree of spatial autocorrelation among sample points was defined by semivariogram models, which were obtained by plotting the semivariance (the average degree of similarity between the values recorded in pairs of sample points separated by a lag distance) against the geographic distance between sample points, $h$.

The semivariance was calculated as:

$$
g(h)=\sum_{i=1}^{N(h)}\left(x_{i}-x_{i+h}\right)^{2} / N(h)
$$

where $x_{i}$ is the value of the variable being studied at Point $i$, and $x_{i+h}$ is the value of the same variable at a 
point at distance $h . N(h)$ is the number of point pairs which are $h$ units apart. In this equation the semivariance is a function of $h$ and contains information about processes occurring on different scales (Rossi et al. 1992). The semivariance generally increases with increasing distance, and it is inversely related to the spatial autocorrelation of the variable. Two important components of the semivariograms are the 'nugget variance' and the 'range'. The 'nugget' exists when $g(0)$ is not equal to zero and the model fitting the semivariance is not constrained to go through the origin. The 'nugget' has been interpreted as the variability of the study process within a sampling unit and may be due to the sampling design error relative to the discontinuous nature of the process in space. The 'range' is the sampling distance between points where the semivariance reaches its maximum value. The semivariogram asymptotically approaches this maximum, and it represents the distance beyond which the spatial autocorrelation in the study process is zero. The range can be used to identify patterns of spatial independence when the process has a constant mean across space.

The significant interpolated maps were obtained by kriging algorithm (Matheron 1963), a geostatistical gridding method which attempts to express trends that are suggested in data, so that high points might be connected along a ridge, rather than isolated by bull's- eye type contours. A cross validation was conducted to compare the estimated and observed values for the statistical verification of the interpolation model. Semivariograms as well as kriged maps were obtained using the GEO-EAS software developed by EPA (Environmental Protection Agency, Englund \& Sparks 1988).

\section{RESULTS}

\section{Reed mass loss and detritus colonizers}

The mass loss during the $30 \mathrm{~d}$ of submersion showed the best fit with the Olson (1963) exponential model of decomposition. Differences in the rate were observed among seasons (2-way ANOVA, p $<0.001$ among seasons). The reed half-life was longer in winter-spring (December to January and March to April) than in summer-fall (June to July and September to October). In particular, the winter and fall collections showed the longest and the shortest half-lives, respectively (Table 2). We also observed significant differences between protected and unprotected litter bags: both the annual mean (2-way ANOVA, p $<0.01$ among treatments) and the seasonal variation, expressed as CV\% (Variance ratio-test, p < 0.0001), of the reed half-life were longer in the protected leaf packs than in the unprotected ones (Table <3). In summer-fall, however, the half-life was shorter in the protected leaf packs than in the unprotected ones (Table 2).

Thirty-four invertebrate taxa were found on the unprotected litter bags. Most animals were detritivores: 6 taxa were collectors, whereas 4 and 12 taxa were represented by shredders and scrapers, respectively (Table 4). A variety of scraper and collector species exhibited erratic seasonal patterns of variation, whereas the density of the most abundant scraper species, as well as all the shredders, was mainly related to the season and the site. Filter feeders and predators were not common in the bags. On annual average, the reed half-life significantly declined with the increasing abundance of shredders and scrapers across the lake $\left(y=71.28-1.04 x, r^{2}=0.46, p<0.01\right)$; the other functional groups were not significantly related to leaf decay.

Microbial oxygen demand was related to the reed half-life (Fig. 2). In particular, measurements carried out on the 
leaves protected from the detritivores showed that oxygen demand was positively related to both the reed mass loss $\left(y=10.52 \ln x+27.82, \mathrm{r}^{2}=0.55, \mathrm{p}<\right.$ $0.001)$ and the percentage of fungal colonization $(y=$ $\left.55.67 x^{1.07}, r^{2}=0.29, p<0.05\right)$. A detailed analysis of fungi and detritivore-fungi interactions will be reported elsewhere (Rossi \& Costantini unpubl.). The protected litter bags consumed more oxygen than the unprotected ones in summer-fall ( $t$-test, $\mathrm{p}<0.01$ ), while the difference was not significant in winterspring (Fig. 2). Furthermore, in summer-fall the oxygen demand measured on the unprotected litter bags declined as the total abundance of shredders and scrapers increased $\left(y=1.39-0.17 \log x_{i} r^{2}=0.30\right.$, $\mathrm{p}<0.05)$

\section{Intra-habitat variations}

The spatial dependency for all the measured variables was analyzed but, though most of them showed high spatial variability, only 4 (the annual mean and the seasonal variability of the animal-colonized reed half-life; salinity; and dissolved oxygen) gave significant spatial patterns and statistically validated maps (Table 5, Figs. 3 to 6).

Table 3. Annual average and seasonal variability (CV\%) of the reed half-life of litterbags unprotected and protected from animals (days), and the shredder and scraper abundance (ind. $\mathrm{g}^{-1}$ ). The lake sites are ordered from south to north (see Fig. 1)

\begin{tabular}{|rccccrr|r}
\hline Site & $\begin{array}{c}\text { Unprotected } \\
\text { litterbags }\end{array}$ & \multicolumn{2}{c}{$\begin{array}{c}\text { Protected } \\
\text { litterbags }\end{array}$} & \multicolumn{3}{c|}{$\begin{array}{c}\text { Animal } \\
\text { abundance }\end{array}$} \\
& Mean CV $(\%)$ & Mean CV $(\%)$ & Mean & CV $(\%)$ \\
\hline 4 & 59.49 & 12.26 & 66.30 & 58.64 & 8.77 & 58.29 \\
3 & 59.29 & 24.10 & 91.40 & 51.60 & 4.15 & 129.83 \\
14 & 63.00 & 25.23 & 79.98 & 54.32 & 5.58 & 99.87 \\
16 & 65.20 & 22.33 & 76.55 & 49.23 & 6.89 & 106.11 \\
15 & 64.25 & 23.89 & 80.34 & 59.98 & 4.37 & 110.98 \\
20 & 66.25 & 26.13 & 53.45 & 57.34 & 4.49 & 67.88 \\
2 & 59.39 & 28.76 & 70.07 & 50.78 & 6.28 & 56.24 \\
1 & 71.89 & 24.55 & 74.84 & 64.45 & 3.18 & 54.20 \\
12 & 70.92 & 20.19 & 67.18 & 48.68 & 1.56 & 68.53 \\
6 & 66.87 & 26.65 & 72.14 & 43.97 & 9.99 & 128.36 \\
5 & 63.67 & 32.67 & 64.10 & 54.09 & 5.21 & 61.90 \\
19 & 67.75 & 27.81 & 78.11 & 65.20 & 5.62 & 83.90 \\
7 & 67.08 & 29.39 & 73.73 & 62.27 & 6.70 & 94.91 \\
8 & 67.94 & 28.63 & 56.83 & 76.99 & 8.77 & 73.26 \\
13 & 73.65 & 21.84 & 97.55 & 63.47 & 0.38 & 116.39 \\
18 & 66.25 & 30.12 & 83.12 & 70.23 & 6.89 & 91.54 \\
9 & 61.79 & 57.08 & 59.76 & 75.91 & 10.10 & 49.90 \\
11 & 55.39 & 41.53 & 62.01 & 65.81 & 10.93 & 57.01 \\
10 & 58.66 & 41.33 & 59.70 & 46.60 & 12.01 & 110.27 \\
17 & 59.10 & 44.91 & 60.23 & 54.67 & 10.47 & 94.98 \\
& & & & & & \\
Mean & 64.39 & 29.47 & 71.37 & 58.71 & 6.62 & 85.72 \\
& & & & & & & \\
\hline
\end{tabular}

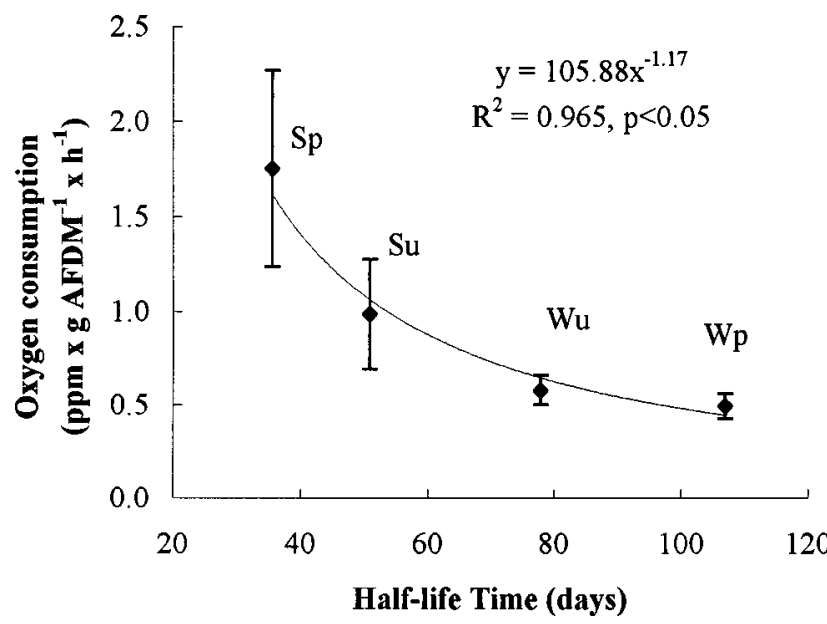

Fig. 2. Regression between the reed half-life time and the microbial oxygen consumption ( $\mathrm{W}=$ winter-spring, $\mathrm{S}=$ summer-fall, $\mathrm{p}=$ protected and $\mathrm{u}=$ unprotected litterbags). The bars represent $\pm \mathrm{SD}$

\section{Decomposition}

Mass loss from the unprotected litter bags started showing significant spatial variability after $10 \mathrm{~d}$ of immersion, when it amounted to more than 11 to $21 \%$ of the initial mass (Table 2). The rate of leaf breakdown varied across the lake in every season (ANCOVA F-test, $\mathrm{p}<0.05)$, but the spatial heterogeneity of the reed half-life was significantly higher in summer-fall than in winter-spring $(\mathrm{CV}=20.5 \%$ vs $\mathrm{CV}=11 \%$; variance ratio-test, $\mathrm{p}<0.01$ ).

The analysis of the spatial variance pointed out the statistically significant autocorrelative structure of the half-life time within the study area. The semivariogram of the mean annual values gave a regularly increasing variance up to a distance lag of $660 \mathrm{~m}$ (range), which roughly corresponds to one-fifth of the lake length (Fig. 3, Table 5). The map showed the patchy structure of the process with the highest half-life time in the central area, equidistant from freshwater and seawater inputs (Fig. 4). However the values decreased at a higher rate northwesterly than southwesterly. No spatial structure was observed for the decay of the reed protected from the detritivore colonisation.

Semivariance calculated on the seasonal variability (as CV\%) increased with the distance classes, having a 'range' of $37000 \mathrm{~m}$ (Fig. 3, Table 5). As a result, process variability had a monotonic, not patchy, trend across the lake with the highest values in the northwestern corner. Variability dropped to one half over the $400 \mathrm{~m}$ toward the lake center and to one third over the $2400 \mathrm{~m}$ to the southern end of the lake (Fig. 5). The grid-point facing the northwestern freshwater input (Site 9) was the most variable during the year among 
Table 4. List of taxa associated to the $30 \mathrm{~d}$ submerged leaf bags. The mean $( \pm 2 \mathrm{SE})$ abundance (ind. $\left.\mathrm{g}^{-1}\right)$ per site and spatial heterogeneity (ANOVA: $\left.{ }^{*} \mathrm{p}<0.05,{ }^{* *} \mathrm{p}<0.01\right)$ are reported. Shredder and scraper species diversity $\left(H_{\mathrm{s}} \pm 2 \mathrm{SE}\right.$; Shannon \& Weaver 1949) is also shown

\begin{tabular}{|c|c|c|c|c|}
\hline & Jun-Jul & Sep-Oct & Dec-Jan & Mar-Apr \\
\hline \multicolumn{5}{|l|}{ Shredders } \\
\hline \multicolumn{5}{|l|}{ Crustacea } \\
\hline Idotea baltica (Pallas) & $0.238 \pm 0.205^{* *}$ & $0.011 \pm 0.013$ & $0.023 \pm 0.036^{*}$ & 0 \\
\hline Gammarus insensibilis Stock & $4.296 \pm 2.225^{*}$ & $0.205 \pm 0.329$ & $0.966 \pm 0.877^{* *}$ & $2.049 \pm 1.414^{*}$ \\
\hline Melita palmata (Montagu) & $1.027 \pm 0.648^{* *}$ & $0.387 \pm 0.293^{* *}$ & $0.100 \pm 0.109^{* *}$ & $0.073 \pm 0.088$ \\
\hline Microdeutopus grillotalpa A. Costa & $0.120 \pm 0.140$ & $11.962 \pm 7.178$ & $4.256 \pm 3.288$ & $0.435 \pm 0.458^{*}$ \\
\hline \multicolumn{5}{|l|}{ Scrapers } \\
\hline \multicolumn{5}{|l|}{ Crustacea } \\
\hline Lekanesphaera monodi Arcangeli & $2.795 \pm 2.300^{*}$ & $1.924 \pm 1.994$ & $0.546 \pm 0.302^{* *}$ & $0.066 \pm 0.064$ \\
\hline Sphaeroma serratum (Fabricius) & 0 & 0 & $0.034 \pm 0.030$ & 0 \\
\hline \multicolumn{5}{|l|}{ Gastropoda } \\
\hline Bittium reticulatum (Da Costa) & $6.496 \pm 2.815$ & $5.889 \pm 3.694^{*}$ & $0.057 \pm 0.047$ & $0.658 \pm 0.833^{* *}$ \\
\hline Cerithium rupestre Risso & $0.092 \pm 0.061$ & $0.130 \pm 0.116$ & $0.015 \pm 0.018$ & $0.025 \pm 0.032^{* *}$ \\
\hline Odostomia sp. & $0.326 \pm 0.256^{*}$ & $1.007 \pm 1.104^{* *}$ & $0.065 \pm 0.058^{* *}$ & $0.352 \pm 0.511^{* *}$ \\
\hline Gibbula adansoni (Payraudeau) & $0.081 \pm 0.081$ & $0.053 \pm 0.046$ & 0 & $0.016 \pm 0.021$ \\
\hline Alvania lineata Risso & $0.637 \pm 0.355$ & $0.214 \pm 0.115$ & $0.024 \pm 0.027$ & $0.081 \pm 0.107^{* *}$ \\
\hline Alvania cimex (Linneo) & $0.004 \pm 0.007$ & 0 & 0 & 0 \\
\hline Rissoa ventricosa Desmarest & $0.006 \pm 0.012$ & 0 & 0 & 0 \\
\hline Putilla sp. & $0.005 \pm 0.009$ & $0.051 \pm 0.101$ & 0 & 0 \\
\hline Lunatia sp. & $0.007 \pm 0.015$ & 0 & 0 & 0 \\
\hline Haminoea navicula (Da Costa) & 0 & 0 & 0 & $0.002 \pm 0.004$ \\
\hline Species diversity $\left(H_{\mathrm{s}}\right)$ & $1.229 \pm 0.090$ & $0.827 \pm 0.131$ & $0.936 \pm 0.141^{* *}$ & $0.866 \pm 0.150^{*}$ \\
\hline \multicolumn{5}{|l|}{ Collectors } \\
\hline \multicolumn{5}{|l|}{ Polychaeta } \\
\hline Phyllodocidae & $0.057 \pm 0.084$ & 0 & 0 & 0 \\
\hline Syllis sp. & 0 & $0.018 \pm 0.036$ & 0 & 0 \\
\hline Oligochaeta & 0 & 0 & $0.004 \pm 0.008$ & 0 \\
\hline \multicolumn{5}{|l|}{ Crustacea } \\
\hline Tanaidacea & $3.009 \pm 2.435$ & $6.566 \pm 3.555$ & $0.127 \pm 0.129$ & $0.151 \pm 0.095^{* *}$ \\
\hline Corophium insidiosum Crawford & $7.593 \pm 9.106$ & $5.769 \pm 10.297^{* *}$ & $2.471 \pm 2.258$ & $9.672 \pm 8.637$ \\
\hline \multicolumn{5}{|l|}{ Diptera } \\
\hline Chironomidae (l.) & $0.293 \pm 0.578$ & $0.126 \pm 0.129$ & $0.002 \pm 0.004$ & $0.027 \pm 0.032$ \\
\hline \multicolumn{5}{|l|}{ Filterers } \\
\hline \multicolumn{5}{|l|}{ Bivalvia } \\
\hline Mytilus galloprovincialis Lamarck & $0.404 \pm 0.229$ & $0.083 \pm 0.069^{* *}$ & $0.004 \pm 0.006^{*}$ & $0.497 \pm 0.391$ \\
\hline \multicolumn{5}{|l|}{ Gastropoda } \\
\hline Cerastoderma glaucum (Poiret) & $0.043 \pm 0.029^{*}$ & 0 & 0 & 0 \\
\hline Macoma cumana (O.G. Costa) & $0.283 \pm 0.274$ & 0 & 0 & 0 \\
\hline \multicolumn{5}{|l|}{ Predators } \\
\hline Turbellaria & 0 & $0.009 \pm 0.018$ & $0.002 \pm 0.004$ & 0 \\
\hline \multicolumn{5}{|l|}{ Gastropoda } \\
\hline Buccinulum corneum (Linneo) & $0.008 \pm 0.012$ & $0.003 \pm 0.006$ & 0 & 0 \\
\hline Cyclope neritea (Linneo) & $0.057 \pm 0.102^{* *}$ & $0.006 \pm 0.012^{*}$ & 0 & 0 \\
\hline Amyclina corniculus (Olivi) & $0.003 \pm 0.007$ & 0 & 0 & 0 \\
\hline Hexaplex trunculus (Linneo) & 0 & $0.006 \pm 0.008$ & $0.002 \pm 0.004$ & 0 \\
\hline Nassarius mutabilis (Linneo) & 0 & $0.034 \pm 0.069$ & 0 & 0 \\
\hline \multicolumn{5}{|l|}{ Polychaeta } \\
\hline Nereis sp. & $0.243 \pm 0.123$ & $0.494 \pm 0.292$ & $0.030 \pm 0.037$ & $0.086 \pm 0.059^{* *}$ \\
\hline \multicolumn{5}{|l|}{ Crustacea } \\
\hline Penaeus sp. & 0 & $0.094 \pm 0.099^{* *}$ & $0.036 \pm 0.027^{* *}$ & $0.009 \pm 0.012^{*}$ \\
\hline Carcinus mediterraneus (Czerniavsky) & $0.101 \pm 0.093^{*}$ & $0.053 \pm 0.079^{* *}$ & $0.010 \pm 0.013$ & $0.011 \pm 0.015$ \\
\hline
\end{tabular}


Table 5. Variogram model parameters and sample variance $\left(\mathrm{s}^{2}\right)$ for the variables with significant autocorrelation and spatial map. All models fit the Gaussian curve (Gaussian model: $g(h)=C_{0}+C\left(1-\mathrm{e}^{-h^{2} / a^{2}}\right.$ ), where $h=$ separation distance and $a=$ spatial range). $C_{0}=$ nugget variance, $C /\left(C_{0}+C\right)$ $=$ structural variance, $C$, expressed as a proportion of model sample variance; range $=$ distance over which the structural variance is expressed. See Fig. 4 for variograms

\begin{tabular}{|lrrrr|}
\hline \multirow{2}{*}{ Variable } & \multicolumn{4}{c|}{ Model parameters } \\
& $C /\left(C_{0}+C\right)$ & Range $(\mathrm{m})$ & \multicolumn{1}{c|}{$\mathrm{r}^{2}$} & \multicolumn{1}{c|}{$\mathrm{s}^{2}$} \\
\hline Half-life time & 0.57 & 663.33 & 0.71 & 31.33 \\
Half-life time variability & 1.00 & 37118.26 & 0.90 & 134045.44 \\
Salinity & 0.85 & 1763.21 & 0.96 & 38.64 \\
Dissolved $\mathrm{O}_{2}$ & 0.18 & 683.84 & 0.72 & 0.16 \\
\hline
\end{tabular}

all the study sites, having the slowest decay rate in winter. The widest homogeneous area of variability was located in the lake center. The semivariogram showed high nugget effect (i.e. the variance was high at distance (lag) 0; Rossi et al. 1992), which accounted for the highest rate of spatial change among all the variables under study.

\section{Riparian influence}

A significant inverse relationship between the unprotected reed half-life and the 'RL' index was found (Fig. 7a). By contrast, the process seasonal variability increased with the index (Fig. 7b). This means that as reedcover, sinuosity, and vicinity of the site to shoreline increased, the reed half-life time decreased, but its seasonal variability increased. When considering the single variables of the index (distance, sinuosity and reed-cover), both decomposition variables (mean annual half-life and its CV\%) showed only weak correlations with the reed-cover $(r=-0.47$ and $r=0.52$, $\mathrm{p}<0.05)$. No relationships between the half-life of the protected litter bags and the index or its single component were found.

\section{Sediment organic matter}

The organic matter content of sediments varied among sites (1-way ANOVA, $\mathrm{p}<0.0001$ ). The mean annual percentage was $8.24 \pm 1.58 \%$, but 2 groups of sites with very different mean values could be distinguished (Fig. 8a; K-means clustering, 1-way ANOVA, $\mathrm{p}<0.0001)$. The highest percentage was detected at Sites 1, 4, 12, 13, 15 and $17(18.07 \pm 1.85 \%)$, while at the remaining sites the organic component was only $6.29 \pm 0.32 \%$ of the total deposition amount. Most of

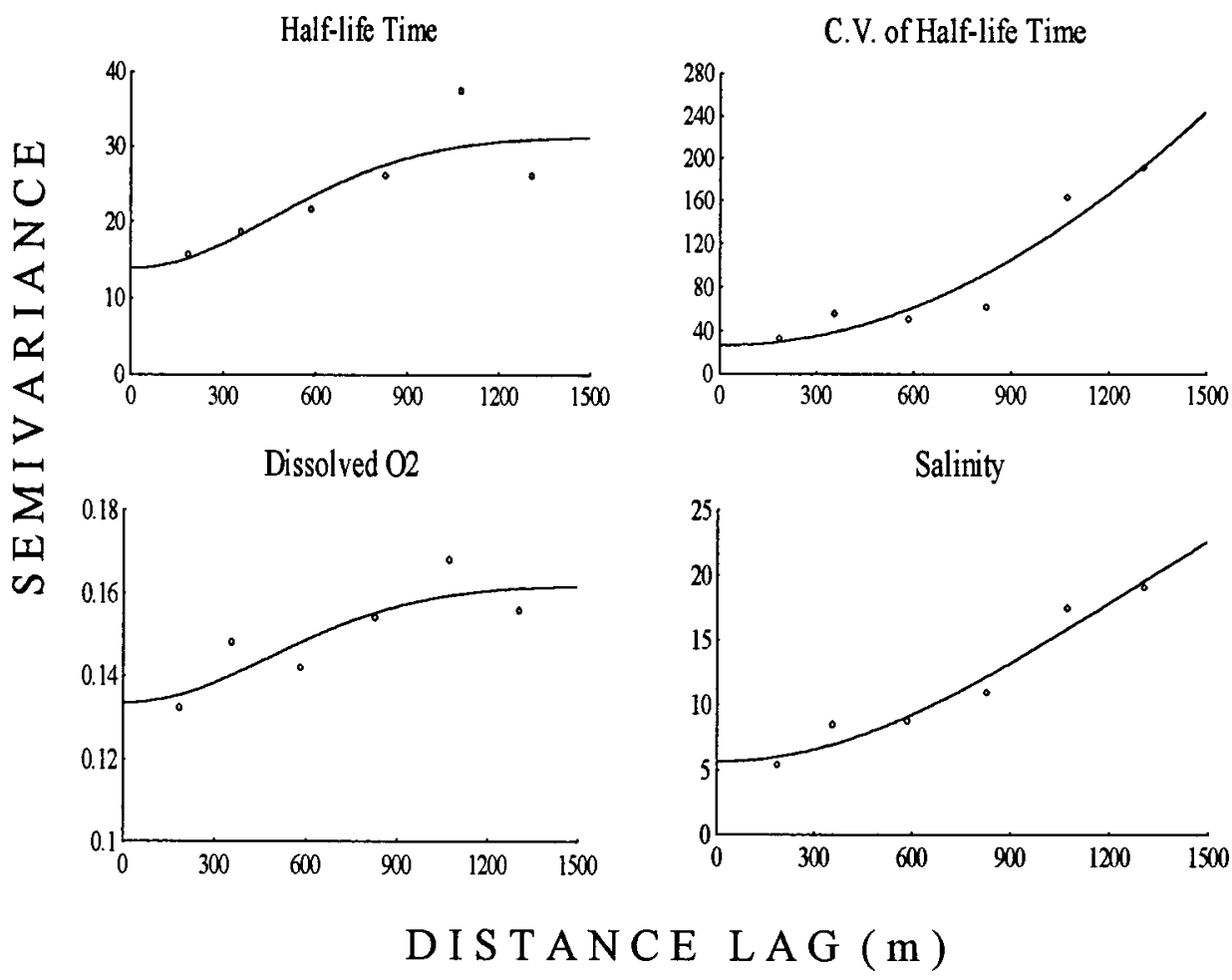

Fig. 3. Semivariograms of decomposition (annual average and variability of reed half-life time) and chemical variables (salinity and dissolved $\mathrm{O}_{2}$ ) having significant autocorrelation and spatial map 


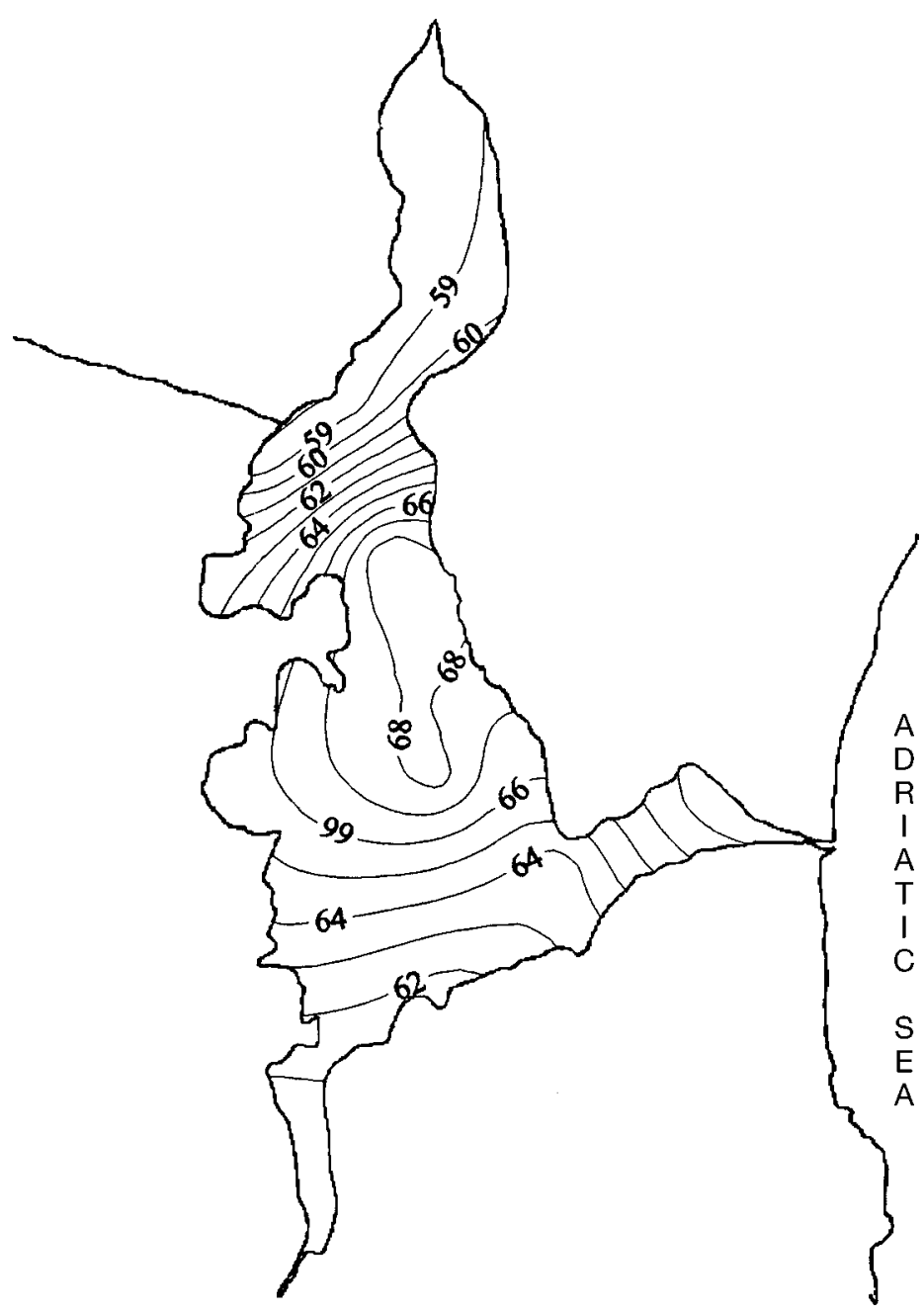

Fig. 4. Interpolation map by kriging based on the half-life time (days) of Phragmites australis. Values are reported on the map

the organic matter $(64.75 \pm 2.75 \%)$ was found in the finest size-fraction with particle diameter less than $0.5 \mathrm{~mm}$, but it was differently distributed among sizegrades in the 2 different groups of sites. In fact, in the first group the finest fraction accounted for $91.50 \pm$ $2.09 \%$ of the total organic deposition, while it was only $55.02 \pm 2.80 \%$ in the second one. Despite the differences observed among sites, patterns did not show significant spatial structure (i.e. the variance between pairs of sampling sites was not related with their spatial distance).

Organic matter also varied seasonally, yet the highest variability was measured in the northern area $(\mathrm{CV}$ was, on average, $61.85 \%$ for Sites $8,9,10,11,17$, and 18 and $29.19 \%$ for the remaining sites).

The percentage of organic matter and reed half-life time were positively related $(\mathrm{r}=0.65, \mathrm{p}<0.01)$.

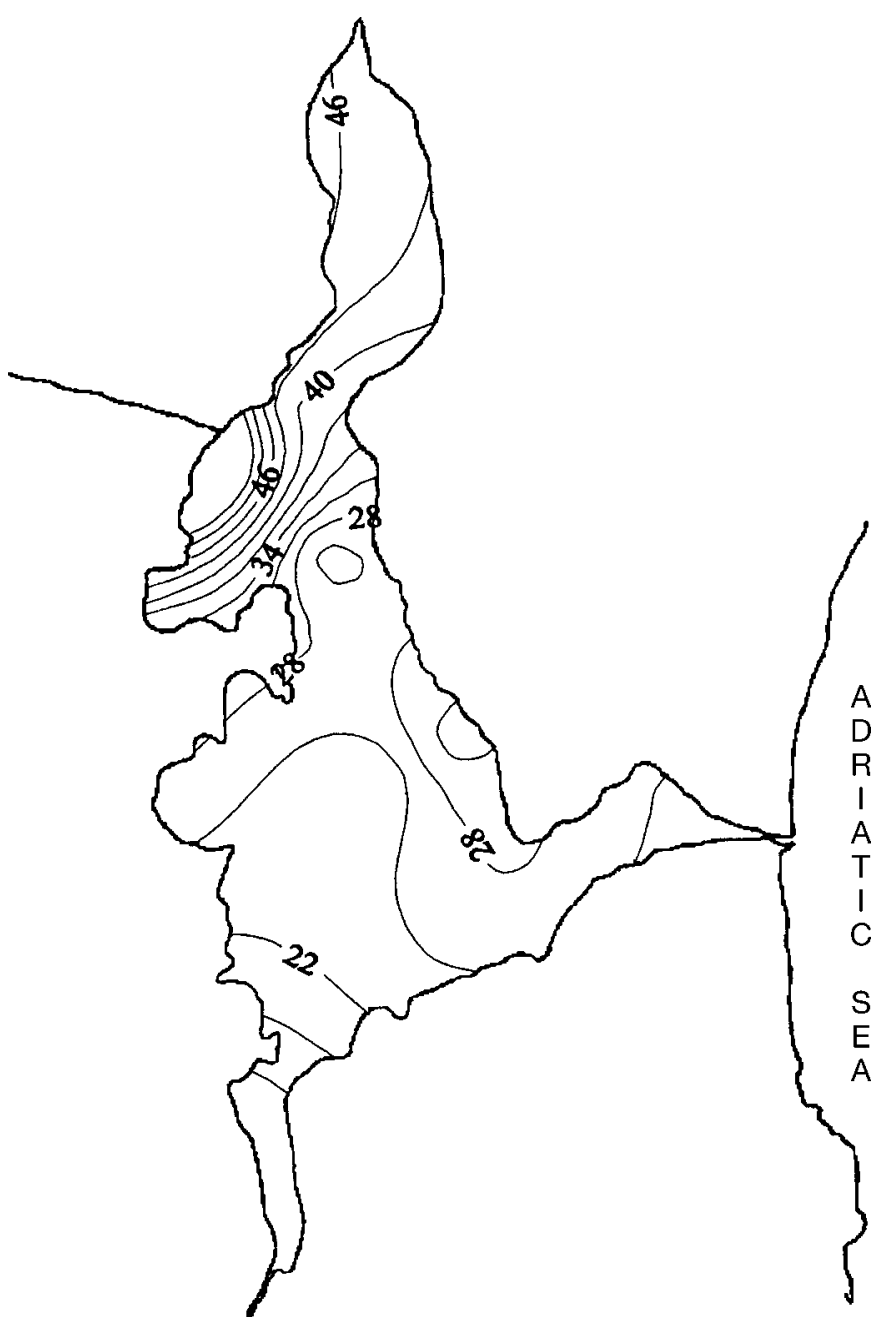

Fig. 5. Interpolation map by kriging based on half-life variability (CV\%) of Phragmites australis. Values are reported on the map

\section{Abiotic factors}

Salinity and dissolved oxygen were spatially structured as shown by semivariograms and maps (Figs. 3 \& $6 \mathrm{a}, \mathrm{b})$. The 'ranges' were 176 and $680 \mathrm{~m}$, respectively (Table 4). Depending on freshwater and marine influences, salinity varied from 5 to $41 \%$ o during the year, with the greatest seasonal variability in front of the freshwater inputs, especially the southern one (Table 6). By averaging all the sampling dates, the highest rates of spatial change were observed in the sites close to the main northern tributary and to the marshy area, while freshwater from the southern reserve exerted its influence on a wider, more homogenous, area (Fig. 6a). Dissolved oxygen was also unevenly distributed, and reached the lowest average values in the northern area (Fig. 6b). Its seasonal vari- 

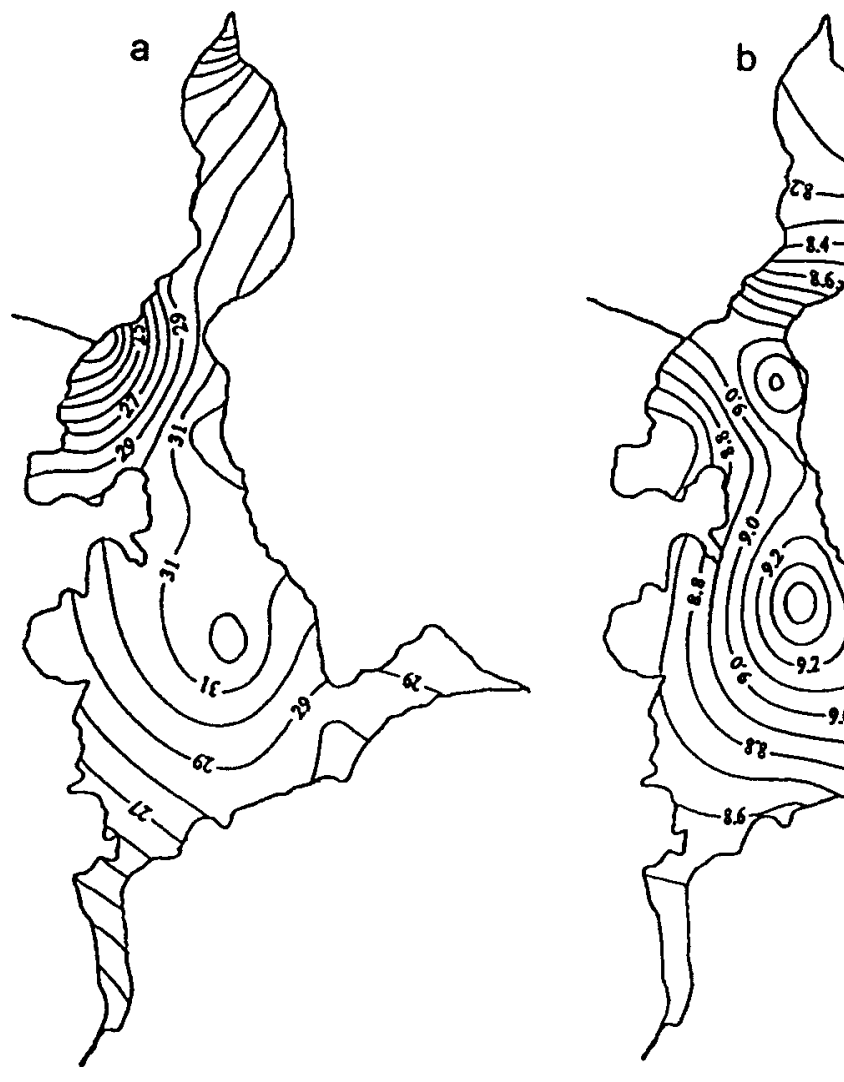

Fig. 6. Interpolation map by kriging based on (a) salinity (\%o) and (b) dissolved $\mathrm{O}_{2}\left(\mathrm{ml} \mathrm{l}^{-1}\right)$. Values are reported on the map

ability decreased in the lake center, while peaking towards the southern freshwater input. In summer-fall, dissolved $\mathrm{O}_{2}$ decreased with the increasing percentage of organic matter in the sediments $\left(y=8.61 \mathrm{e}^{-0.014 x}, \mathrm{r}^{2}=\right.$ 0.37, $\mathrm{p}<0.01$ ).

Salinity and dissolved $\mathrm{O}_{2}$ were positively related to the mean annual half-life time of the unprotected packs $\left(y_{\text {(salinity) }}=0.72 x+43.73, \mathrm{r}^{2}=0.25, \mathrm{p}<0.05\right.$; $y_{\text {(oxygen) }}=7.01 x+3.97, \mathrm{r}^{2}=0.33, \mathrm{p}<0.01$ ). Such relationships were not found for the protected packs.

Water temperature varied seasonally ranging from $26^{\circ} \mathrm{C}$ in summer and $13^{\circ} \mathrm{C}$ in winter, but neither significant difference among sites (1-way ANOVA, ns) nor spatial structure were found. Consistently, reed decomposition was not significantly related with the temperature on the spatial scale.

\section{Detritivores}

The total animal mass temporally increased with the temperature in accordance to the animal abundance $\left(y_{\text {mass }}=0.32 x_{t}{ }^{\circ} \mathrm{C}+2.92, \mathrm{r}^{2}=0.12, \mathrm{p}<0.01\right)$. The highest mean annual abundance of shredders and scrapers was found in sites close to the main freshwater inputs, while the lowest was in the lake center (Table 3). In the littoral sites, the abundance also varied with the percentage of shoreline reed-cover $(\mathrm{r}=0.67, \mathrm{p}<$ 0.01). Yet distribution was not significantly, spatially structured, though related to dissolved $\mathrm{O}_{2}(\mathrm{r}=$ $-0.74, \mathrm{p}<0.001)$, salinity $(\mathrm{r}=-0.46$, $\mathrm{p}<0.05$ ), and sediment organic content. In particular, shredders and scrapers significantly declined with the organic enrichment in the bottom depositions, while collectors increased $(\mathrm{r}=-0.51$ and $\mathrm{r}=$ $0.55, \mathrm{p}<0.05$, respectively). Cluster analysis based on functional group abundance and organic matter data gave similar patterns of site association (Fig. 8b).
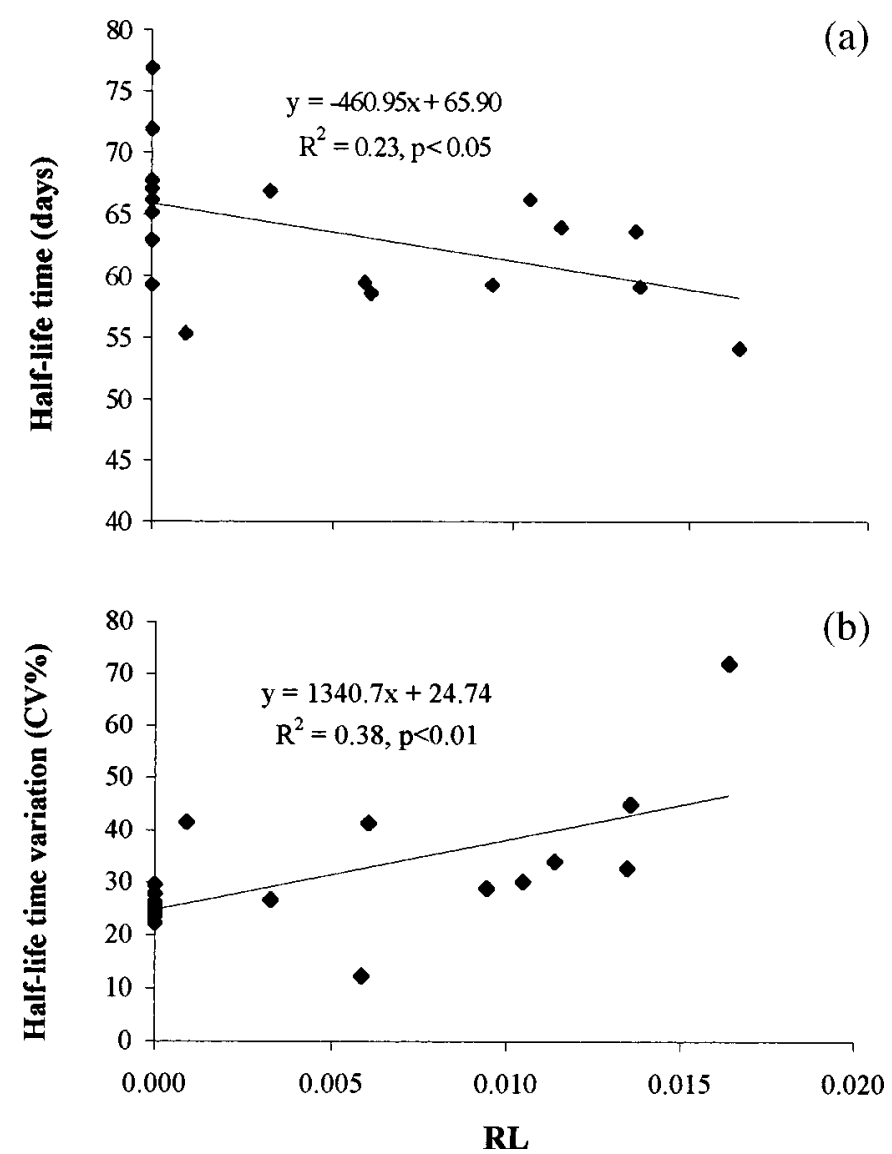

Fig. 7. Regressions between both (a) reed half-life average and (b) variability, and the 'RL' index 


\section{DISCUSSION}

\section{Leaf mass loss}

Classical studies on decomposition have generally been carried out for longer periods of observation than ours (e.g. Post \& de la Cruz 1977, Valiela et al. 1985). However, in our latitudes a considerable part of leaf mass is lost within a few weeks from immersion, while leaching occurs during the first days (Short et al. 1980, Webster \& Benfield 1986). In Lake Alimini, leaf mass loss became significantly different among sites after $20 \mathrm{~d}$ of submersion, and the $30 \mathrm{~d}$ immersion was largely sufficient to assess the decomposition pattern.

One-month mass loss data fitted the classical exponential model allowing us to use half-life time as an intuitive measure of decomposition rate, and to have statistically significant differentiation. Since water temperature did not vary significantly across the lake, we did not perform degree-day transformation of data so as to deal with the actual leaf mass losses. Mean Phragmites australis half-life time varied from 55 to $60 \mathrm{~d}$ at the northern and southern areas of the lake to 70 to $75 \mathrm{~d}$ in the central area and on the seaward side of the lake. The values are consistent with those obtained in brackish Mediterranean environments (Fazi 1994) and assign P. australis to the 'fast decomposition resource' category according to Petersen \& Cummins' classification (1974). Similar studies conducted in various freshwater habitats reported slower decay rates than those assessed in the present study (Mason \& Bryant 1975, Polunin 1982, Tanaka 1991). Faster decomposition may be ascribed to the mild annual temperature of the mid-Mediterranean area. Differences could also stem from the experimental treatment of the leaf material (Newell 1996). For example, P. australis may undergo an initial colonization by aeroaquatic fungi, which influence decay dynamics once underwater. Therefore, the absolute value of the decay rate might be altered because of the oven drying before use, but this did not betray the aims of our study, which was a comparative one. The age of leaves may also influence the decomposition rate (green leaves lose mass faster than old ones). The high spatial heterogeneity reported in the present paper, however, was not imputable to the leaf material, which was homogeneous at the start of the study.

Both salinity and dissolved $\mathrm{O}_{2}$ were inversely related to the reed mass loss, but no obvious mechanisms for this effect were evident. We may suppose that their influence on the process was mediated by animals since none of them affected the mass loss of protected litterbags. Furthermore, salinity was significantly related to the detritivore abundance. Dissolved $\mathrm{O}_{2}$ was higher in open water, where decomposition was slower, but was likely controlled by environmental factors others than oxygen concentration (e.g. low detritivore occurence). Little evidence of the influence of salinity and $\mathrm{O}_{2}$ has been available from the literature (see Webster \& Benfield 1986 for a review). Salinity affected decomposition in vitro (Suzuki \& Matsukawa 
Table 6. Mean statistics of temperature, salinity, and dissolved oxygen in Lake Alimini during the experimental study. Sites are ordered from south to north (see Fig.1)

\begin{tabular}{|c|c|c|c|c|c|c|c|c|c|}
\hline \multirow[t]{2}{*}{ Site } & \multicolumn{3}{|c|}{ Temperature $\left({ }^{\circ} \mathrm{C}\right)$} & \multicolumn{3}{|c|}{ Salinity (\%o) } & \multicolumn{3}{|c|}{ Dissolved $\mathrm{O}_{2}\left(\mathrm{ml} \mathrm{l}^{-1}\right)$} \\
\hline & Mean & $\mathrm{SD}$ & Min-Max & Mean & $\mathrm{SD}$ & Min-Max & Mean & $\mathrm{SD}$ & Min-Max \\
\hline 4 & 18.69 & 8.53 & $5.5-29.5$ & 21.35 & $11.6 \mathrm{c}$ & $5.0-41.0$ & 8.45 & 1.87 & $5.7-12.2$ \\
\hline 3 & 18.96 & 7.66 & $5.9-28.1$ & 27.86 & 4.44 & $21.0-36.0$ & 8.55 & 1.69 & $6.4-11.6$ \\
\hline 14 & 18.93 & 7.54 & $5.7-28.5$ & 27.99 & 3.41 & $22.5-36.0$ & 8.58 & 1.69 & $6.4-11.5$ \\
\hline 16 & 18.78 & 8.30 & $5.9-28.7$ & 26.56 & 4.72 & $18.5-36.5$ & 8.43 & 1.96 & $5.9-11.2$ \\
\hline 15 & 16.99 & 8.27 & $8.8-27.2$ & 32.68 & 2.55 & $29.0-38.5$ & 8.52 & 1.53 & $7.0-10.6$ \\
\hline 20 & 19.24 & 7.92 & $8.5-28.4$ & 29.24 & 4.95 & $22.5-38.0$ & 8.65 & 1.32 & $7.2-11.1$ \\
\hline 2 & 18.67 & 7.55 & $7.4-28.6$ & 27.82 & 6.41 & $12.0-37.0$ & 9.07 & 1.44 & $6.8-11.6$ \\
\hline 1 & 19.32 & 7.02 & $9.4-28.6$ & 29.31 & 4.96 & $20.5-37.0$ & 8.68 & 1.34 & $6.1-10.4$ \\
\hline 12 & 17.72 & 6.49 & $9.7-26.8$ & 32.56 & 2.65 & $30.0-38.0$ & 9.52 & 1.04 & $7.9-10.9$ \\
\hline 6 & 18.67 & 7.65 & $6.7-29.0$ & 29.60 & 5.05 & $20.0-37.0$ & 8.75 & 1.05 & $7.1-10.5$ \\
\hline 5 & 18.68 & 7.01 & $7.8-28.5$ & 30.29 & 4.81 & $24.0-41.0$ & 9.05 & 0.90 & $7.4-10.6$ \\
\hline 19 & 17.72 & 6.79 & $7.0-28.5$ & 30.56 & 2.75 & $26.5-40.0$ & 8.28 & 1.43 & $7.3-10.5$ \\
\hline 7 & 18.25 & 7.28 & $6.9-28.7$ & 30.40 & 5.80 & $22.0-41.0$ & 8.87 & 1.21 & $7.1-11.0$ \\
\hline 8 & 19.28 & 7.46 & $6.2-28.6$ & 30.07 & 5.06 & $22.0-40.0$ & 8.52 & 1.40 & $5.5-10.5$ \\
\hline 13 & 17.59 & 6.46 & $7.0-26.8$ & 32.40 & 2.07 & $29.0-35.0$ & 9.36 & 0.97 & $7.8-10.5$ \\
\hline 18 & 18.79 & 6.89 & $7.4-28.4$ & 32.40 & 2.54 & $29.5-36.5$ & 8.36 & 1.23 & $7.5-11.1$ \\
\hline 9 & 18.52 & 6.29 & $7.6-26.1$ & 20.77 & 5.46 & $10.0-31.0$ & 8.32 & 1.24 & $7.2-11.3$ \\
\hline 11 & 19.62 & 6.41 & $10.0-28.7$ & 29.26 & 4.56 & $22.0-35.0$ & 8.28 & 1.21 & $6.6-10.3$ \\
\hline 10 & 18.51 & 6.88 & $7.7-28.9$ & 31.13 & 4.37 & $25.0-39.0$ & 8.03 & 1.37 & $6.0-10.0$ \\
\hline 17 & 18.58 & 6.88 & $7.6-28.9$ & 24.32 & 8.32 & $12.5-40.0$ & 8.01 & 1.34 & $5.5-10.8$ \\
\hline $\mathrm{CV}$ & 3.50 & & & 11.77 & & & 4.64 & & \\
\hline
\end{tabular}

munity mass (Barlocher 1980, Newell \& Barlocher 1993). Reduction in the mass loss of unprotected leaves with respect to the protected ones should, therefore, be ascribed to the animal overgrazing on microflora. In summer-fall we recorded a decrease in the microbial $\mathrm{O}_{2}$ uptake on the reed packs grazed by animals, in accordance with Maraun \& Scheu (1996). Moreover, $\mathrm{O}_{2}$ demand of unprotected leaves declined with increasing macrodetritivore abundance, consistent with the hypothesis of microflora reduction due to overgrazing. Therefore, while accelerating decomposition at intermediate abundance, detritivores seem to overgraze microbes at very high densities, thus reducing the potential decomposition rate (measured by the protected litterbags). The

1987), but results were inconsistent in the field. No apparent effect of dissolved $\mathrm{O}_{2}$ both in the field and lab has been found.

Direct influences of chemicals from the adjacent agro-ecosystem on detritus processing were not determined in this study. Laboratory studies on nutrient effect on leaf decomposition have nearly always demonstrated rapid leaf mass loss when nutrient availability was great (Webster \& Benfield 1986), but effects have been variable in the field.

\section{Microorganism-detritivore interactions}

Whenever the decay rates have been examined on site scale, the variance has been explained by changes in microorganism-animal interactions (e.g. Basset \& Rossi 1984, Menendez et al. 1989). In Lake Alimini, mass loss increased with detritivore abundance. Nevertheless, the influence exerted by detritivores on leaf processing was complex. In summer-fall protected litterbags decayed faster than the unprotected ones. The reverse occurred in winter-spring when both animal abundance and, thus, feeding were lower. Mass loss from protected bags was mainly due to the enzymatic activity of microorganisms that colonized the vegetal detritus. Detritivores feed on the microbial-colonized detritus (Odum \& de la Cruz 1967, Rossi et al. 1983, Rossi 1985), causing a reduction of the microbial com- results are consistent with data from studies on terrestrial systems which showed that, when the detritivore density was maximized, microbial respiration was less than control values (Hanlon \& Anderson 1980).

The interactions between detritivores and microflora are likely to determine the low temporal variability that characterizes the decomposition process. In fact, mass loss from the protected litterbags experienced very wide seasonal fluctuations, mainly determined by microbial activities which are sensitive to changes of climatic and chemical factors. Seasonal variability significantly decreased when the presence of detritivores was allowed.

\section{Spatial patterns}

Reed decomposition changed more rapidly on both spatial and temporal scales in the northern area of the basin than in the southern one. The central area was characterized by the slowest leaf mass loss as well as intermediate values of mass loss seasonal variability. Both decomposition variables (half-life average and $\mathrm{CV}$ ), in addition to salinity and dissolved $\mathrm{O}_{2}$, were spatially autocorrelated, whereas other variables were not spatially structured. In particular, animal abundance varied between sites, relating to many environmental factors, but it would have probably required a smaller sample grid than that considered in this study. In fact, 
the patchy distribution of populations can be caused by population processes such as migration, reproduction, and mortality, which occur on scales smaller than those of ecosystem processes. In spite of scale differences, however, the reed mass loss from the unprotected litterbags and the detritivore abundance were related across the lake. In the absence of animals, leaf mass loss did not show any spatial structure.

Since water temperature varied rather evenly across the lake according to climatic seasonal fluctuations and did not produce any effect on decomposition spatial change, the intra-habitat heterogeneity could be mainly attributed to the influence on biota of hydrodynamics as well as the timing and amount of potential litterfall from the adjacent habitats.

Hydrodynamics not only affect many abiotic factors (such as dissolved $\mathrm{O}_{2}$ and salinity) but, together with the litterfall, they are also responsible for the heterogeneous litter distribution within the lake (see also Reice 1974, 1977, 1980, Snelgrove \& Butman 1994). It has been demonstrated that less than $10 \%$ of leaf litter moves more than $10 \mathrm{~m}$ from the shoreline, and only a part of the finer particles are transported towards the open waters, where also algal detritus accumulates (Davis \& Brubaker 1973, Carpenter 1980, Pieczynska 1990, Rossi et al. 1990). In littoral areas, hydrodynamics are influenced by the shoreline sinuosity. Recesses are characterized by low water turbulence and high accumulation of allochthonous detritus, and provide refuges and foraging areas for detritivores. The quality and amount of litterfall, and the organic matter distribution, in turn, determine specific animal assemblages (Vannote et al. 1980). In Lake Alimini, the relative abundance of detritivore functional groups, which use different detrital particle sizes, changed according to sediment grain size and organic content. Animals colonizing litterbags in muddy, organic-rich areas mostly belonged to the collector functional group, which does not perform leaf fragmentation. The decrease in shredder abundance reduced the rate of leaf breakdown, thus probably causing organic matter to pile up in sediments (see also Rounick \& Winterbourn 1983, Canfield 1989). The low decomposition rate of detritus indicates the 'weak spots' of the aquatic system metabolism, namely those patches which may cause alterations to the lake nutrient regeneration (Rapport et al. 1985, Rapport 1989).

We also found that shredders and scrapers were not abundant close to the littoral Phragmites australis-free areas. Reed cover, together with littoral sinuosity, and the closeness of the sampling site to the shore, was related to the significant spatial structure of the process. The 3 variables seem to synergistically influence the decomposition rate, since the half-life of $P$. australis correlated more strongly with the 'RL' index than with each single index component.
Spatial patterns were even more definite when the temporal variability of the process was considered. Sample grid-points being equal, spatial differentiation in 'processing variance' was greater than in 'processing average' (see semivariograms). The northern area of the lake experienced higher temporal variability than the southern one; furthermore, the higher the temporal variation, the higher the rate of spatial change. Similar trends were found in the seasonal variability of organic deposition on the lake bottom. The northern area was more exposed to riparian influences and, thus, more subject to input variation from adjacent habitats. In fact, the ratio of the length of shoreline to the area of water body was higher on the northern side than on the southern one. Temporal change in macrophyte occurence may also have had a major effect on the northern littoral zone where Phragmites australis covered a great part of the shoreline. In addition, a vast area on the northern side of the lake was characterized by aperiodic flooding, which caused great changes in the riparian profile (sinuosity and average shoreline gradient) and, consequently, in the amounts of decomposing plant litter. Floods and intermittent inputs of rainy waters with associated chemical loads from agricultural activities, substantial in the neighboring territory, may have contributed to the sharp gradient of the process variability observed at the northern side. By contrast, though related to highly variable physico-chemical conditions (in particular, dissolved $\mathrm{O}_{2}$ and salinity), greater and more predictable freshwater inputs from the southern water reserve did not alter markedly the temporal patterns of processing in this area.

The observed between-site variance in decomposition rate shows that, in addition to the rate, spatial variation is an important process feature in the habitat description; this also leads to reconsideration of the role of intra-habitat spatial heterogeneity in establishing the functioning of a complex ecosystem. Habitat patches with different isopleth density may have different speeds of perturbation propagation, as does aggregation of susceptible habitats in landscape (Turner et al. 1989). Moreover, patches characterized by denser isopleths of temporal variability can also turn out to be more difficult to manage than others.

\section{Conclusion}

Spatial analyses allow us to identify system processing 'hot spots'. Therefore, in spite of the increasing application of geostatistical techniques to ecological research (Rossi et al. 1992, Johnston 1993, Villard \& Maurer 1996), greater importance should be given to the mapping of ecosystem functions such as decompo- 
sition rates. Spatial process variability should be considered in simulation models and vulnerability assessment, especially when addressing environmental management. However, since environmental characteristics change locations of boundaries through time (Wiens et al. 1985), process measures including temporal variation may be extremely useful in changing habitats.

As spatial and temporal changes in shallow waters are influenced by external inputs, we propose an index ('RL' index), which takes into account the percentage of plant cover, coastal sinuosity, and distance from the shoreline, to indirectly estimate the rate of allochthonous mass loss. In this perspective, low-elevation multispectral remote sensing might be helpful to determine the relative vegetation cover and the fractal dimension of the basin belt. Such information, together with climate data, would allow a quick evaluation of the most probable spatial pattern of the decomposition rate in aquatic systems.

Acknowledgments. This research was supported by MURST (ex-40\% MPI), EEC (contract ENV4-CT97-0584), and National Technical Service funds. Many thanks to Dr Vittorio Amadio for helpful discussion during the preparatory phases of the research. We also thank Dr Antonio Caputo for the collection and initial processing of data.

\section{LITERATURE CITED}

Bärlocher F (1980) Leaf-eating invertebrates as competitors of aquatic hyphomycetes. Oecologia 47:303-306

Basset A, Rossi L (1984) Leaf processing in stream and lakes of central Italy: role of some environmental factors. Atti Accad Naz Lincei Rend CI Sci Fis Mat Nat LXXVII: 196-204

Bocock KL, Gilbert OL (1957) The disappearance of leaf litter under different woodland conditions. Plant Soil 9: $179-185$

Canfield DE (1989) Sulfate reduction and oxic respiration in marine sediments: implications for organic carbon preservation in euxinic environments. Deep-Sea Res 36(1): 121-138

Carpenter SR (1980) Enrichment of Lake Wingra, Wisconsin, by submersed macrophyte decay. Ecology 61:1442-1452

Carpenter SR (1982) Comparisons of equations for decay of leaf litter in tree-hole ecosystems. Oikos 39:17-22

Cummins KW (1974) Structure and function of stream ecosystem. Bioscience 24:631-641

Cummins KW, Wilzbach MA, Gates DM, Perry JB, Taliaferro WB (1989) Shredders and riparian vegetation. Bioscience 39:24-30

Davis MB, Brubaker LR (1973) Differential sedimentation of pollen grain in lakes. Limnol Oceanogr 18:635-646

Englund E, Sparks A (1988) Geo-EAS user's guide. EPA Report, Las Vegas, NV

Fazi S (1994) Studio del sistema a base detrito in acque salmastre: disponibilità trofica per i detritivori e rapporti strutturali nella comunità. $\mathrm{PhD}$ thesis, University of Rome 'La Sapienza'
Fazi S, Rossi L (1996) Decomposition of leaf litter in saltmarsh ecosystem: weight loss rates vs. community metabolism. Soc Ital Ecol Atti 17:435-438

Gallardo A, Merino J (1993) Leaf decomposition in two Mediterranean ecosystems of southwest Spain: influence of substrate quality. Ecology 74:152-161

Hanlon RDG, Anderson JM (1980) Influence of macroarthropod feeding activities on microflora in decomposing oak leaves. Soil Biol Biochem 12:255-261

Johnston CA (1993) Material fluxes across wetland ecotones in northern landscapes. Ecol Appl 3:424-440

Levin SA (1992) The problem of pattern and scale in ecology. Ecology 73:1943-1967

Li H, Reynolds JF (1994) A simulation experiment to quantify spatial heterogeneity in categorical maps. Ecology 75: 2446-2455

Lousier JD, Parkinson D (1976) Litter decomposition in a cool temperate deciduous forest. Can J Bot 54:419-436

Macchia F (1967) Vegetazione e flora dei laghi Alimini. Atti Relazioni Accad Pugliese Sci 25:1-49

Mann KH (1988) Production and use of detritus in various freshwater, estuarine, and coastal marine ecosystems. Limnol Oceanogr 33:910-930

Marano G, Vaccarella R, Casavola N (1974) Note idrobiologiche sui laghi Alimini. Atti IV Simp Naz Conservaz Nat:427-450

Maraun M, Scheu S (1996) Changes in microbial biomass, respiration and nutrient status of beech (Fagus sylvatica) leaf litter processed by millipedes (Glomeris marginata). Oecologia 107:131-140

Mason CF, Bryant RJ (1975) Production nutrient content and decomposition of Phragmites communis Trin. and Typha angustifolia L. J Ecol 63:71-95

Matheron G (1963) Principles of geostatistics. Econ Geol 58: 1246-1266

Menendez M, Fores E, Comin FA (1989) Ruppia cirrhosadecomposition in a coastal temperate lagoon as affected by macroinvertebrates. Arch Hydrobiol 117:39-48

Newell SY (1996) Established and potential impacts of eukaryotic mycelial decomposers in marine/terrestrial ecotones. J Exp Mar Biol Ecol 200:187-206

Newell SY, Barlocher F (1993) Removal of fungal and total organic matter from decaying cordgrass leaves by shredder snails. J Exp Mar Biol Ecol 171:39-49

Odum EP, de la Cruz AA (1967) Detritus as major component of ecosystem. Bioscience 13:39-40

Olson JS (1963) Energy storage and the balance of producers and decomposers in ecological systems. Ecology 44: 322-331

Petersen RC, Cummins KW (1974) Leaf processing in a woodland stream. Freshw Biol 4:343-368

Pieczynska E (1990) Lentic aquatic-terrestrial ecotones: their structure, function, and importance. In: Naiman RJ, Decamps $\mathrm{H}$ (eds) The ecology and management of aquatic-terrestrial ecotones. UNESCO, Paris

Polunin NVC (1982) Processes contributing to the decay of reed (Phragmites australis) litter in fresh water. Arch Hydrobiol 94:182-209

Post HA, de la Cruz AA (1977) Litterfall, litter decomposition, and flux of particulate organic material in a coastal plain stream. Hydrobiologia 55:201-207

Rapport DJ (1989) What constitutes ecosystem health? Perspect Biol Med 33:120-132

Rapport DJ, Regier HA, Hutchinson TC (1985) Ecosystem behavior under stress. Am Nat 125:617-640

Reice SR (1974) Environmental patchiness and the breakdown of leaf litter in a woodland stream. Ecology 55:1271-1282 
Reice SR (1977) The role of animal association, current velocity and sediment in lotic litter decomposition. Oikos 29: 357-365

Reice SR (1980) The role of substratum in benthic macroinvertebrate microdistribution and litter decomposition in a woodland stream. Ecology 61:580-590

Riedl R (1991) Fauna e flora del Mediterraneo. Franco Muzzio \& $\mathrm{C}$, Padova

Rosa F, Blosch J, Rathke DE (1994) Sampling the settling and suspended particulate matter. In: Murdoch A, MacKnight SD (eds) Handbook of techniques for aquatic sediments sampling. Lewis Publishers, Inc, Boca Raton, p 97-131

Rossi L (1985) Interactions between invertebrates and microfungi in freshwater ecosystems. Oikos 44:175-184

Rossi L, Basset A, Nobile L (1983) A coadapted trophic niche in two species of crustacea (Isopoda): Asellus aquaticus (L.) and Proasellus coxalis Dolff. Evolution 37:810-820

Rossi L, Basset A, Picciafuoco L (1987) Dinamica ecosistemica della struttura detritica. In: Università degli Studi di Roma 'La Sapienza' (ed) Valutazione della situazione ambientale del Lago di Nemi. Provincia di Roma, Roma, p 217-237

Rossi L, Picciafuoco L, Basset A (1990) Depth-time distributions of detritus depositions in Lake Nemi (volcanic lake of central Italy). Hydrobiologia 202:185-195

Rossi RE, Mulla DJ, Journel AG, Franz EH (1992) Geostatistical tools for modeling and interpreting ecological spatial dependence. Ecol Monogr 62:277-314

Rounick JS, Winterbourn MJ (1983) Leaf processing in two contrasting beech forest streams: effect of physical and biotic factors on litter breakdown. Arch Hydrobiol 96: 448-474

Saunders GW (1980) Organic matter and decomposers. In: Le Cren ED, Lowe-McConnell RH (eds) The functioning of freshwater ecosystems. Cambridge University Press, Cambridge, p 341-392

Shannon CE, Weaver W (1949) The mathematical theory of communication. University of Illinois Press, Urbana, IL

Short RA, Canton SP, Ward JV (1980) Detrital processing and

Editorial responsibility: John Austin (Assistant Editor),

Oldendorf/Luhe, Germany associated macroinvertebrates in a Colorado mountain stream. Ecology 61:727-732

Snelgrove PR, Butman CA (1994) Animal-sediment relationships revisited: cause versus effect. Oceanogr Mar Biol Annu Rev 32:111-177

Suzuki T, Matsukawa Y (1987) Hydrography and budget of dissolved total nitrogen and dissolved oxygen in the stratified season in Mikawa Bay, Japan. J Oceanogr Soc Jpn 43:37-48

Tanaka Y (1991) Microbial decomposition of reed (Phragmites communis) leaves in a saline lake. Hydrobiologia 220: $119-129$

Turner MG (1989) Landscape ecology: the effect of pattern on process. Annu Rev Ecol Syst 20:171-197

Turner MG, Gardner RH, Dale VH, O'Neill RV (1989) Predicting the spread of disturbance across heterogeneous landscapes. Oikos 55:121-129

Turner MG, Arthaud GJ, Engstrom RT, Hejl SJ, Liu J, Loeb S, McKelvey K (1995) Usefulness of spatially explicit population models in land management. Ecol Appl 5:12-16

Valiela I, Teal JM, Allen SD, Van Etten R, Goehringer D, Volkmann S (1985) Decomposition in salt marsh ecosystems: the phases and major factors affecting disappearance of above-ground organic matter. J Exp Mar Biol Ecol 89:29-54

Vannote RL, Minshall GW, Cummins KW, Sedall JR, Cushing CE (1980) The river continuum concept. Can J Fish Aquat Sci 37:130-137

Villard MA, Maurer BA (1996) Geostatistics as a tool for examining hypothesized declines in migratory songbirds. Ecology 77:59-68

Watt AS (1947) Pattern and process in the plant community. J Ecol 35:1-22

Webster JR, Benfield EF (1986) Vascular plant breakdown in freshwater ecosystems. Annu Rev Ecol Syst 17:567-594

Wiens JA, Crawford CS, Gosz JR (1985) Boundary dynamics: a conceptual framework for studying ecosystems. Oikos 45:421-427

Zar JH (1984) Biostatistical analysis. Prentice Hall, Englewood Cliffs, NJ

Submitted: October 14, 1999; Accepted: February 17, 2000

Proofs received from author(s): August 3, 2000 